
\title{
$\angle S$ Research Suare \\ Is Opium Use Associated with an Increased Risk of Lung Cancer? A Case-Control Study
}

\author{
Ahmad Naghibzadeh Tahami \\ Kerman University of Medical Sciences \\ Maryam Marzban \\ Bushehr University of Medical Sciences \\ Vahid Yazdi Feyzabadi \\ Kerman University of Medical Sciences \\ Shahryar Dabiri \\ Kerman University of Medical Sciences \\ Shokrollah Mohseni \\ Hormozgan University of Medical Sciences \\ Reza Abbasi Rayeni \\ Kerman University of Medical Sciences \\ Mitra Samareh Fekri \\ Kerman University of Medical Sciences \\ Mohammad Hasan Larizadeh \\ Kerman University of Medical Sciences \\ Behnaz karimpoor \\ Kerman University of Medical Sciences \\ Narges Khanjani ( $\nabla$ narges.khanjani@gmail.com ) \\ Kerman University of Medical Sciences
}

\section{Research article}

Keywords: Opium, Risk factor, Lung neoplasm, Case-control

Posted Date: October 2nd, 2019

DOl: https://doi.org/10.21203/rs.2.15585/v1

License: (9) This work is licensed under a Creative Commons Attribution 4.0 International License. Read Full License 
Version of Record: A version of this preprint was published on August 26th, 2020. See the published version at https://doi.org/10.1186/s12885-020-07296-0. 


\section{Abstract}

Background: In recent years, lung cancer (LC) incidence has increased in Iran. The use of opium and its derivatives (O\&D) has increased as well. The aim of this study was to investigate the association between the use of O\&D and LC incidence. Methods: In this case-control study conducted in Kerman, Iran; 140 patients with lung cancer and 284 healthy controls matched by age, sex, and place of residence were included. Data including O\&D use, cigarette smoking, alcohol use, and diet were collected using a structured questionnaire. The relation between the use of O\&D and LC was evaluated using conditional logistic regression test. Results: The use of opium was associated with an increased risk of LC (Adjusted Odds Ratio $(A O R)=7.95,95 \%$ Cl: $3.78-16.73)$. A significant dose-response relation between the use of opium and its derivatives was observed (low use AOR $=7.47,95 \% \mathrm{Cl}: 2.33-23.98$ and high use AOR = $11.57,95 \% \mathrm{Cl}: 2.25-59.49)$. Also, there was a relation between starting to use $0 \& \mathrm{D}$ at lower ages and an increased risk of $L C(A O R=5.78,95 \% \mathrm{Cl}: 2.36-14.14)$. Conclusion: The results of this study support that opium use could be considered as a strong risk factor for LC. Thus, it is highly suggested that tailored policies to be applied in order to reduce use of opium.

\section{Background}

Lung cancer (LC) is the most common type of cancer in the world (1) and from 1.8 million annual cases of LC, which is $12.9 \%$ of all diagnosed cancer cases, more than 1.6 million deaths happen(2). There is a wide geographical variation in the incidence and mortality rates of this disease around the world(3). According to the reports, the incidence of this disease increased rapidly in the first half of the 20th century, and in the late 20th century it became the first preventable cause of death in the world (4). More than half of all LC cases occur in developed countries, including Iran(5).According to reports, in Iran, LC is considered as the 5th most common cancer, and in the last 10 years, it has steadily increased in both genders (male and female)(6), although its incidence in men is more than women (7). In 2012, 4361 deaths were reported from LC in Iran, which is respectively $9.8 \%$ and $6.8 \%$ of mortality due to common cancers happening among men and women(8). The incidence of LC has been reported from 4.7 to 9.2 in 100,000 men and 1.5 to 4.6 in 100,000 women in different world countries (5). Smoking has been known as the most important risk factor for $\operatorname{LC}(9,10)$, and is attributed to more than $90-50 \%$ of LC cases(5). Other risk factors include environmental and occupational exposures, second hand smoke, air pollution, heavy metals and chemical exposure (11-13).

Recent studies have shown that opium and its derivatives (O\&D) are a risk factor for many malignant diseases, including lung (14), gastric(15), esophageal (16), colorectal $(17,18)$, pancreatic(19), bladder (20) and laryngeal cancer(21).

Evidence shows the high prevalence of opioids use in the world. It is estimated that about $0.3-0.5 \%$ (12-21 billion people) of the world population aged 15-64 years, had a history of O\&D use in 2009(22). 
In European countries in 2010, the prevalence of O\&D use was estimated to be 2.6 to 21 per 1000 adults (23), while the prevalence of O\&D use in some populations in Iran is currently estimated to be about $20 \%$ (24) and is considered as the most important type of drug abuse (25). According to one study from the north of Iran, about $17 \%$ of the population aged 40 and over, had a history of O\&D use(26). Some researchers think this may be the reason for the high incidence of esophageal cancer in the north of Iran (16). In Kerman, a city in the south-east of Iran, the prevalence of O\&D use has been estimated to be between $11 \%$ and $15 \%$ in the adult population $(27,28)$. Recently, in a study conducted on hospital inpatients and their companions in Kerman, the prevalence of self-reported O\&D use, was $36.5 \%$ in patients and $19.3 \%$ among their healthy companions (29) and this shows the high prevalence of O\&D use in this region.

Although, studies have been conducted about the relation between O\&D use and LC, but some have not included other risk factors including smoking, alcohol, and diet (14). This case-control study was performed to investigate the relation between O\&D use and LC in a population with a relatively high prevalence of opioid use.

\section{Methods}

\section{Samples and data source}

In this matched case-control study, 140 patients with LC whose pathologic information was available at the Cancer Registry of Kerman University of Medical Sciences, and were diagnosed between January 2014 and December 2017, were included.

The sample size was estimated 174 cases based on the odds ratio of at least 2.0, the minimum O\&D use in the general population $=0.2 \%$, the control to case ratio of 2 , power $=0.8$, and type one error $=0.05$.

Patients' information including their home address, telephone number and cancer type were extracted from their medical records. A telephone call was made to the patients and/or their families for asking permission. Then a specific date and time was set for an interview and people were visited in person and interviewed.

In a systematic method, the first two neighbors on the right side of the cases' home who matched the inclusion criteria and were willing to cooperate, were selected as the controls. Both controls were matched for age $( \pm 5)$ and gender. If the control was not home or did not want to cooperate, the next eligible neighbor was approached. Data from the control group was gathered by face to face interviews similar to the case group. The purpose of the study was explained for all participants and written informed consent was taken before data collection.

\section{Tools and methods of data collection}

Data were collected using a questionnaire. The first part of the questionnaire consisted of demographic information including gender, age, education, and marital status; and the second part asked about the use 
of O\&D, alcohol, cigarette smoking, and diet. The validity and reliability of this questionnaire had been approved in a previous study $(15)$ and this questionnaire was used in similar studies $(15,17,18)$.

The type and amount of O\&D used was questioned. In order to quantify O\&D use and cigarette smoking, the current and past history of exposure was both asked. The daily use of O\&D was measured based on the local measurement unit, Nokhod, which is equal to 0.2 grams. The type of opioids used was divided into four categories: raw opium (Teriak), sap (Shireh), burned opium (Sukhteh), and heroin. However, no one reported the use of heroin or burned opium. The diet part of the questionnaire included dietary habits of Iranians especially residents of this area.

All interviews were conducted by one trained interviewer, and in order to minimize under-reporting of $0 \& D$ use, the interviewer explained the purpose of the study thoroughly and convinced participants that their information would be kept confidential. If the LC case was not alive, the closest family member would be interviewed.

\section{Data analysis}

The cumulative consumption (median daily use $\times$ duration of consumption) was calculated for cigarette, O\&D, and alcohol use, and participants were categorized into three groups: non-users, low users ( $\leq$ median use in the controls), and high users (>median use in the controls). The median use in the control group was considered as a criterion for classifying the population into high and low users. In all analyses, the non-user group was considered as the reference group.

Some patients had started using opioids after being diagnosed with cancer. Therefore, opioid consumption after cancer diagnosis was not considered. Only O\&D use from 2 years before the onset of cancer was investigated.

Conditional logistic regression with $95 \%$ confidence level were used for data analysis. In order to control the effect of confounding variables, only the variables with P-value less than 0.1 in the univariate analysis were added to the final multivariate models Multiplicative interactions between cigarette smoking (ever use) and opium use (ever use and cumulative dose) were evaluated using the likelihood ratio test.

All statistical analyses were performed using STATA (version 14.0, Stata Corp, College Station, TX, USA). Statistical significance levels less than 0.05 were considered significant.

\section{Results}

The initial sample size for this study was 174 LC patients and 348 controls. But 34 patients did not consent to participate and the frequency of non-response was $19.5 \%$. Eventually, 140 cases and 280 controls were included. Among the cases, the majority (68.57\%) were male and married (96.43\%). 
Most of the cases $(60.71 \%)$ were in the 51-70 years age range at the time they entered the study. More than half of the cases had Illiterate or elementary education (62.14\%). As controls were well matched for age, and gender, no significant difference was observed in these variables between cases and controls $(P>0.05)$. Other demographic information about cases and controls are presented in Table 1.

The most common method of opioid use among cases $(93.0 \%)$ and controls $(100 \%)$ was smoking. Table 2 shows the results of O\&D use and cigarette smoking. As shown in this table, $59.22 \%$ of cases and $19.64 \%$ of controls had a history of O\&D use. O\&D use was significantly associated with an increased risk of LC (OR: 7.95; 95\% Cl: 3.78 -16.73).

Low and high daily use of O\&D increased the odds of LC by AOR: 4.80; (95\% Cl: $2.12-10.84)$, and AOR: 12.50; (95\% Cl: $4.72-33.09$ ) times respectively. In addition, O\&D use more than 20 years significantly increased the risk of LC (AOR: 7.26; $95 \% \mathrm{Cl}$ : 1.85-28.52).

Cumulative low and high use of O\&D increased the odds of LC by AOR $=7.47$ (95\% Cl: 2.33-23.98) and 11.57 (95\% Cl: 2.25-59.49) and this shows a dose-response relation between O\&D use and the incidence of LC. The odds of LC in people who started to use O\&D in lower ages was higher (AOR: $5.78 ; 95 \% \mathrm{Cl}$ : 2.36 - 14.14).

About $57 \%$ of cases were smokers, while this rate was $26 \%$ for controls. Univariate (Crude OR= $5.89 ; 95 \%$ Cl: 3.30-10.50), and multivariate analysis showed (AOR: 2.57; 95\% Cl: $1.22-5.42)$ a strong association between smoking and LC.

Daily cigarette smoking was associated with an increased incidence of LC (AOR: 3.26; 95\% Cl: 1.44 -7.34), but a low use of daily cigarette smoking did not show a statistically significant relation with LC (AOR: 1.45; 95\% Cl: 0.51 - 4.10). A long duration of use, was associated with increased risk of LC (AOR: 4.07; $95 \% \mathrm{Cl}: 1.78-9.29)$ and high cumulative cigarette smoking was associated with increased LC (AOR: 3.07; $95 \% \mathrm{Cl}: 1.33-7.05)$ as well. Similarly, there was a significant relation between a lower age at start of cigarette smoking and incidence of LC (AOR: 8.65; 95\% Cl: 2.13 -35.06).

The interaction between cigarette smoking (ever use) and O\&D use (ever use or cumulative dose) was statistically significant $(P=0.03$ and 0.02 , respectively) in the logistic model.

In this study, the prevalence of alcohol use was low and only $3.57 \%$ of the cases and $1.07 \%$ of the controls had a history of alcohol use. In the univariate analysis (OR 3.33; $95 \% \mathrm{Cl}$ : 0.79-13.94) and multivariate analysis (AOR 1.48; 95\% Cl: 0.26-8.36), the odds ratios for alcohol use and LC were not significant.

\section{Discussion}

The results of this study showed that the majority of the patients with lung cancer had a history of O\&D use, and the use of O\&D may be associated with an increased risk of LC. Also, in this study, there was a 
dose-response relation between O\&D use and the risk of LC, and by increased O\&D use, the risk of these types of cancers increased as well.

However, the relation between O\&D use and cancer may be confounded by other risk factors such as age, gender, cigarette smoking, and alcohol use (30). In Iran, opioids consumers are mainly elderly people who are more likely to be cigarette smokers as well(26). However, after adjusting for confounding factors, including cigarette smoking, alcohol use, and diet, the results remained significant.

There are many reasons to suggest a causal relation between O\&D use and LC. The first is the strong odds ratios observed in this study and the fact that O\&D use increased the odds of LC over 7 times. Second, consistent with this study, other studies conducted in Iran have also shown a relation between O\&D use and LC. A study conducted in Tehran, Iran, showed that O\&D use increased the odds of LC over 7 times and consistent with this study, a dose-response relation between LC and opium was reported (14).

However, opioids may also be used to relieve cancer pain. Therefore, in order to prevent reverse causality, the history of O\&D use from two years before the diagnosis of cancer was investigated.

Many mechanisms have been proposed about the carcinogenicity of O\&D. Studies have shown that O\&D and its alkaloids, including morphine have mutagenic effects (31). Empirical studies have shown that pyrolysed opium has mutagenic effects on Salmonella strains (32). Also, pyrolysates and morphine alkaloids have led to sister chromatid exchange in human lymphocytes and morphological changes in cultured Syrian hamster embryo cells (33). They have also caused carcinogenic changes after being injected subcutaneously, inside the trachea, or into the gastrointestinal system of rats (32). It has also been shown that aromatic hydrocarbons released from burning opioids, indirectly lead to DNA damage and, as a result, may stimulate mutagenic mechanisms (34). However, the carcinogenic mechanisms of opium has not been thoroughly identified yet and further studies are required.

It is worth to mention that many chemicals are added to opioids during their processing, which may have carcinogenic effects. One of these chemicals is lead, which is added in order to increase the weight of the product, and let drug dealers make more money. In the studies conducted on opioids and addicted people in Iran, the amount of lead in the opioids and blood samples of addicts was much higher than normal and at levels that could cause severe health effects(35). Studies have investigated the relation between occupational exposure to lead and the risk of lung cancer, it was shown that exposure to lead increased the risk of lung cancer by about three-fold and a dose-response relationship was observed(36).

There was no relationship between alcohol consumption and lung cancer in this study.In Iran, since the vast majority of people are Muslims, the prevalence of alcohol consumption is much lower than other parts of the world (37). Although, in a few previous studies, people who were heavy alcohol users had a relatively low risk of developing lung cancer(38), but here was no heavy alcohol user in this study.

Opioids use has a high prevalence in some parts of Iran and in Kerman province. There is a probability that a significant proportion of lung cancers in Iran may be related to opioids use. Most of the Bradford 
Hill criteria about the causal relation between LC and O\&D use have been met; and temporality, a doseresponse relation, consistency, and a strong association, can be seen in this relation.

This study had some limitations. There is a probability of recall, interviewer, or reporting bias. Underreporting of opium use, especially in controls, was possible, although by standardizing the interview process and employing a trained interviewer to conduct all interviews, researchers tried to minimize this bias.

A strength of this study was using population-based neighbor controls rather than hospital controls, which helped partially control the confounding effects of socio-economic and environmental factors (39). The other strength of this study was the use of a well-designed questionnaire for measuring O\&D use that its validity and reliability had been confirmed in previous studies (15) .

\section{Conclusions}

This study showed that O\&D use may be a risk factor for LC consistent with other studies. The results of this study are consistent with other reports of opium use and cancer, which may most likely indicate the causality of this relationship. However, more studies are required.

\section{References}

1. Rooney C, Sethi T. The epithelial cell and lung cancer: the link between chronic obstructive pulmonary disease and lung cancer. Respiration. 2011;81(2):89-104.

2. Ferlay J, Soerjomataram I, Dikshit R, Eser S, Mathers C, Rebelo M, et al. Cancer incidence and mortality worldwide: sources, methods and major patterns in GLOBOCAN 2012. International journal of cancer. 2015;136(5):E359-E86.

3. Cruz CSD, Tanoue LT, Matthay RA. Lung cancer: epidemiology, etiology, and prevention. Clinics in chest medicine. 2011;32(4):605-44.

4. Alberg AJ, Samet JM. Epidemiology of lung cancer. Chest. 2003;123(1):21S-49S.

5. Garcia M, Jemal A, Ward E, Center M, Hao Y, Siegel R, et al. Global Cancer Facts \& Figures 2007. Atlanta, GA: American Cancer Society, 2007. T. 2007;1:52.

6. Almasi Z, Salehiniya H, Amoori N, Enayatrad M. Epidemiology characteristics and trends of lung cancer incidence in Iran. Asian Pac J Cancer Prev. 2016;17(2):557-62.

7. Kamangar F, Dores GM, Anderson WF. Patterns of cancer incidence, mortality, and prevalence across five continents: defining priorities to reduce cancer disparities in different geographic regions of the world. Journal of clinical oncology. 2006;24(14):2137-50.

8. Khorasani S, Rezaei S, Rashidian H, Daroudi R. Years of potential life lost and productivity costs due to premature cancer-related mortality in Iran. Asian Pac J Cancer Prev. 2015;16(5):1845-50.

9. Adcock IM, Caramori G, Barnes PJ. Chronic obstructive pulmonary disease and lung cancer: new molecular insights. Respiration. 2011;81(4):265-84. 
10. Gompelmann D, Eberhardt R, Herth F. Advanced malignant lung disease: what the specialist can offer. Respiration. 2011;82(2):111-23.

11. Dong G-H, Zhang $P$, Sun $B$, Zhang $L$, Chen $X, M a ~ N$, et al. Long-term exposure to ambient air pollution and respiratory disease mortality in Shenyang, China: a 12-year population-based retrospective cohort study. Respiration. 2012;84(5):360-8.

12. Tummino C, Maldonado F, Laroumagne S, Astoul P, Dutau H. Lung cancer following bronchoscopic lung volume reduction for severe emphysema: a case and its management. Respiration. 2012;83(5):418-20.

13. Königshoff M. Lung cancer in pulmonary fibrosis: tales of epithelial cell plasticity. Respiration. 2011;81(5):353-8.

14. Masjedi MR, Naghan PA, Taslimi S, Yousefifard M, Ebrahimi SM, Khosravi A, et al. Opium could be considered an independent risk factor for lung cancer: a case-control study. Respiration. 2013;85(2):112-8.

15. Naghibzadeh Tahami A, Khanjani N, Yazdi Feyzabadi V, Varzandeh M, Haghdoost AA. Opium as a risk factor for upper gastrointestinal cancers: a population-based case-control study in Iran. Archives of Iranian medicine. 2014;17(1):2-6.

16. Nasrollahzadeh D, Kamangar F, Aghcheli K, Sotoudeh M, Islami F, Abnet C, et al. Opium, tobacco, and alcohol use in relation to oesophageal squamous cell carcinoma in a high-risk area of Iran. British journal of cancer. 2008;98(11):1857.

17. Lankarani KB, Khosravizadegan Z, Naghibzadeh-Tahami A, Akbari M, Khodadost M, Honarvar B, et al. Opium use and risk of lower gastrointestinal cancers: Population-based case-control study in South of Iran. International Journal of Cancer Management. 2017;10(6).

18. Naghibzadeh-Tahami A, Yazdi-Feyzabadi V, Khanjani N, Ashrafi-Asgarabad A, Alizaeh H, BORHANINEJAD VR, et al. Can Opium Use Contribute to a Higher Risk of Colorectal Cancers? A Matched Case-control Study in Iran. Iranian journal of public health. 2016;45(10):1322.

19. Moossavi S, Mohamadnejad M, Pourshams A, Poustchi H, Islami F, Sharafkhah M, et al. Opium Use and Risk of Pancreatic Cancer: A Prospective Cohort Study. Cancer Epidemiology and Prevention Biomarkers. 2018;27(3):268-73.

20. Akbari M, Naghibzadeh-Tahami A, Khanjani N, Baneshi MR, Kamali E, Hesampour M, et al. Opium as a Risk Factor for Bladder Cancer: A Population-based Case-control Study in Iran. Archives of Iranian medicine. 2015;18(9):567-71.

21. Mousavi MRA, Damghani MA, Haghdoust AA, Khamesipour A. Opium and risk of laryngeal cancer. The Laryngoscope. 2003;113(11):1939-43.

22. Rahmati A, Shakeri R, Khademi H, Poutschi H, Pourshams A, Etemadi A, et al. Mortality from respiratory diseases associated with opium use: a population-based cohort study. Thorax. 2017;72(11):1028-34.

23. Malekzadeh MM, Khademi H, Pourshams A, Etemadi A, Poustchi $H$, Bagheri $M$, et al. Opium use and risk of mortality from digestive diseases: a prospective cohort study. The American journal of 
gastroenterology. 2013;108(11):1757.

24. Drugs UNOo, Crime. World drug report 2010: United Nations Publications; 2010.

25. McAdam-Marx C, Roland CL, Cleveland J, Oderda GM. Costs of opioid abuse and misuse determined from a Medicaid database. Journal of pain \& palliative care pharmacotherapy. 2010;24(1):5-18.

26. Pourshams A, Khademi H, Malekshah AF, Islami F, Nouraei M, Sadjadi AR, et al. Cohort profile: the Golestan Cohort Study-a prospective study of oesophageal cancer in northern Iran. International journal of epidemiology. 2009;39(1):52-9.

27. Nakhaee N, Divsalar K, Meimandi MS, Dabiri S. Estimating the prevalence of opiates use by unlinked anonymous urine drug testing: a pilot study in Iran. Substance use \& misuse. 2008;43(3-4):513-20.

28. Najafipour H, Masoomi M, Shahesmaeili A, Haghdoost AA, Afshari M, Nasri HR, et al. Effects of opium consumption on coronary artery disease risk factors and oral health: Results of Kerman Coronary Artery Disease Risk factors Study a population-based survey on 5900 subjects aged 15-75 years. International journal of preventive medicine. 2015;6.

29. Rashidian H, Hadji M, Marzban M, Gholipour M, Rahimi-Movaghar A, Kamangar F, et al. Sensitivity of self-reported opioid use in case-control studies: Healthy individuals versus hospitalized patients. PloS one. 2017;12(8):e0183017.

30. Shakeri R, Kamangar F, Mohamadnejad M, Tabrizi R, Zamani F, Mohamadkhani A, et al. Opium use, cigarette smoking, and alcohol consumption in relation to pancreatic cancer. Medicine. 2016;95(28).

31. Friesen M, O'neill I, Malaveille C, Garren L, Hautefeuille A, Cabral J, et al. Characterization and identification of 6 mutagens in opium pyrolysates implicated in oesophagel cancer in Iran. Mutation Research/Fundamental and Molecular Mechanisms of Mutagenesis. 1985;150(1-2):177-91.

32. Perry P, Thomson E, Day N, Bartsch H. Induction of SCE by opium pyrolysates in $\mathrm{CHO}$ cells and human peripheral blood lymphocytes. Carcinogenesis. 1983;4(2):227-30.

33. Hewer T, Rose E, Ghadirian P, Castegnaro M, Malaveille C, Bartsch H, et al. Ingested mutagens from opium and tobacco pyrolysis products and cancer of the oesophagus. The Lancet. 1978;312(8088):494-6.

34. Kamangar F, Chow W-H, Abnet CC, Dawsey SM. Environmental causes of esophageal cancer. Gastroenterology Clinics of North America. 2009;38(1):27-57.

35. Hayatbakhsh MM, Oghabian Z, Conlon E, Nakhaee S, Amirabadizadeh AR, Zahedi MJ, et al. Lead poisoning among opium users in Iran: an emerging health hazard. Substance abuse treatment, prevention, and policy. 2017;12(1):43.

36. Lundström N-G, Nordberg G, Englyst V, Gerhardsson L, Hagmar L, Jin T, et al. Cumulative lead exposure in relation to mortality and lung cancer morbidity in a cohort of primary smelter workers. Scandinavian journal of work, environment \& health. 1997:24-30.

37. Mozafarinia R, Assarian M, Ziaaddini A. Prevalence of Substance Abuse among Students of Tehran University of Medical Sciences, Iran. Addiction \& health. 2017;9(2):103. 
38. Bagnardi V, Randi G, Lubin J, Consonni D, Lam TK, Subar AF, et al. Alcohol consumption and lung cancer risk in the Environment and Genetics in Lung Cancer Etiology (EAGLE) study. American journal of epidemiology. 2009;171(1):36-44.

39. Shakeri R, Kamangar F, Nasrollahzadeh D, Nouraie M, Khademi H, Etemadi A, et al. Is opium a real risk factor for esophageal cancer or just a methodological artifact? Hospital and neighborhood controls in case-control studies. PloS one. 2012;7(3):e32711.

\section{Declarations}

\section{Acknowledgements}

Authors would like to gratitude all the study participants for their collaboration in response to the questions of the face to face interviews. We also thank the Mr Pouya Dehghani who interviewed the participants. Authors also would like to thank the Physiology Research Center affiliated with Kerman University of Medical Sciences (KUMS) for the its financial support and facilitating this research.

\section{Funding}

This study was partly financed by Physiology Research Center affiliated with Kerman University of Medical Sciences (KUMS) with grant number 95000555. The funding bodies were not involved in the study design, study execution, or the writing of this manuscript.

\section{Availability of data and materials}

The datasets generated during and/or analysed during the present study are available from the corresponding author on reasonable request.

\section{Authors' contributions}

ANT and NKH were contributed to the study design, data analysis and led the preparation of the original manuscript. ANT, VYF and MM were involved in data manipulation and conducting the statistical analyses and drafting the manuscript. SHD, MSF, MHL, RAR and BK contributed to consultations and facilitating the data collection and helped supervise the project. They also provided mentoring in the implementation of the study and assisted in the preparation of the manuscript. All authors read and approved the final version of the manuscript.

\section{Ethics approval and consent to participate}

The study got approved by the ethics committee of Kerman University of Medical Sciences (KUMS) with ID number IR.KMU.REC. 1396.1093. Ethical considerations were taken into account during data collection and analysis. Any questions asked about the study by the participant were discussed in full and the written informed consent was obtained from the participants before starting the data collection. It was assured that confidentiality would be maintained, and that no personal information would be identified in 
any publications arising from the study. Participants were informed that participation was entirely voluntary and they could withdraw at any time.

\section{Consent for publication}

Not applicable.

\section{Competing interests}

The authors declare that they have no competing interests.

\section{Tables}

Table 1. Demographic variables in case and control groups 


\begin{tabular}{|c|c|c|c|}
\hline Variable & Lung Cancers & Matched Controls & \multirow[b]{2}{*}{ P-value* } \\
\hline $\mathrm{N}$ & 140 & 280 & \\
\hline \multicolumn{4}{|l|}{ Gender } \\
\hline Male & $96(68.57)$ & $192(68.57)$ & 1.0 \\
\hline Female & $44(31.43)$ & $88(31.43)$ & \\
\hline Marital status & & & 0.53 \\
\hline Married & $135(96.43)$ & $273(97.50)$ & \\
\hline Single & $5(3.57)$ & $7(2.50)$ & \\
\hline \multicolumn{4}{|l|}{ Age } \\
\hline$\leq 50$ & $35(25.0)$ & $78(27.86)$ & 0.63 \\
\hline $51-70$ & $85(60.71)$ & $170(60.71)$ & \\
\hline$>70$ & $20(14.29)$ & $32(11.43)$ & \\
\hline \multicolumn{4}{|l|}{ Education } \\
\hline \multicolumn{4}{|l|}{ Illiterate or Elementary Education } \\
\hline Middle or High school & $87(62.14)$ & $68(24.29)$ & 0.001 \\
\hline \multirow[t]{2}{*}{ High School Diploma or above } & $42(30.0)$ & $138(49.22)$ & \\
\hline & $11(7.86)$ & $74(26.43)$ & \\
\hline
\end{tabular}

*P-value calculated according to McNemar's test

Table 2. The association between the use of opioids and its derivatives, smoking and the incidence of lung cancer 
Opium use

Never

Ever

Amount of daily opium use

Never used

SMedian (4.5 grams per day)††

$>$ Median

\section{Duration}

Never used

$\leq$ Median (20 years) $\dagger \dagger$

$>$ Median
57 (40. $\quad 225$ (80.36)

71)

83 (59.22)

57 (40.71) 225 (80.36)

29 (10.36)

47 (33.57) 26 (9.29)

$57(40.71)$

225 (80.36)

41 (29.29)

30 (10.71)

$42(30.00)$
Referent

$9.73(5.21-18.15)$

Referent

$6.83(3.40-13.73)$

12.46 (5.76- 26.92)

Referent

7.32 (3.70-14.49)

12.98 (5.72- 29.48)
Referent

7.95 (3.78 - 16.73)

Referent

$4.80(2.12$ - 10.84)

$12.50(4.72-33.09)$

Referent

3.58 (1.22-10.55)

$7.26(1.85-28.52)$

\section{Cumulative use of}

Opium†t†

Never used

$\leq$ Median

years) ††

$>$ Median

Age at start of opium use

Never used

$>$ Median

$\leq$ Median (41 years) ††

Cigarette smoking

Never

Ever

Amount of daily tobacco use

Never used

$\leq$ Median (33 cigarettes per day) $+\dagger$

$>$ Median

Duration

Never used

$\leq$ Median (30 years) $\dagger \dagger$

$>$ Median
$59(42.14) \quad 205(73.21)$

57 (40.71) 225 (80.36)

$22(15.71) \quad 27$ (9.64)

61 (43.57) 28 (10.00)

59 (42.14) 205 (73.21)

81 (57.86)

75 (26.79)

$40(14.29)$

$58(41.43) \quad 35(12.50)$

59 (42.14) 205 (73.21)

40 (28.57)

$42(15.00)$

41 (29.29)
Referent

4.22 (1.44-12.30)

$8.60(1.77-41.63)$

Referent

5.69 (2.40-13.47)

$11.90(6.02-23.53)$

Referent

5.89 (3.30-10.50)

Referent

3.19 (1.54-6.58)

$8.29(4.35-15.79)$

Referent

4.74 (2.49- 9.02)

8.39 (3.90- 18.06)
Referent

7.47 (2.33-23.98)

$11.57(2.25-59.49)$

Referent $3.93(1.22$ - 12.62)

$5.78(2.36-14.14)$

Referent $2.57(1.22-5.42)$

Referent $1.45(0.51-4.10)$

$3.26(1.44-7.34)$

Referent $2.16(1.00-4.65)$ 4.07 (1.78 - 9.29)

\section{Cumulative use of cigarette smoking} t十七

Referent

Referent 


\section{Never used}

$\begin{array}{lllll}\leq \text { Median(49.5 pack-years) } t \dagger & 23(16.43) & 38(13.57) & 3.11(1.52-6.40) & 1.82(0.66-4.97) \\ >\text { Median } & 58(41.43) & 37(13.21) & 9.04(4.60-17.70) & 3.07(1.33-7.05)\end{array}$

Age at start of cigarette smoking

$\begin{array}{lcccc}\text { Never use } & 59(42.14) & 205(73.21) & \text { Referent } & \text { Referent } \\ >\text { Median } & 62(44.29) & 61(95.71) & 5.45(3.01-9.89) & 4.46(1.87-10.61) \\ \text { SMedian (30 years) } \dagger \dagger & 19(13.57) & 14(5.0) & 8.48(3.44-20.85) & 8.65(2.13-35.06)\end{array}$

\section{Alcohol Use}

Never

277 (98.93)

Referent

Referent

Ever

† Confounding effect of specific dietary factors such as the use of meat, fruit and vegetables, hydrogenated fats, olive oil, as well as other main exposures (cigarette) and alcohol were controlled. $† \dagger$ Median of use in the control group was considered as a criterion. †††Cumulative use was obtained by multiplying the amount of use (per day) and the duration of use (per year) 